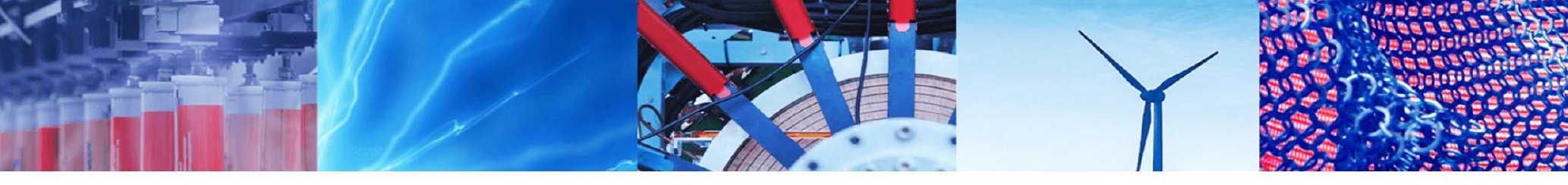

Research Article

\title{
Optimisation of biodiesel production from dairy effluent scum using calcined egg shell as a transesterification catalyst
}

\author{
O. Kuipa ${ }^{1}$-T. S. Marwizi ${ }^{1}$ P. K. Kuipa²
}

Received: 11 June 2020 / Accepted: 15 January 2021 / Published online: 1 February 2021

(C) The Author(s) 2021 OPEN

\begin{abstract}
The production of biodiesel from dairy effluent scum using calcined egg shell as the transesterification catalyst has been explored. Eggshell powder was calcined at $900^{\circ} \mathrm{C}$ for $3 \mathrm{~h}$ and used as catalyst. The influence of methanol-oil molar ratio, catalyst concentration and reaction temperature were studied using Response Surface Methodology employing a Central Composite Rotatable Design. An empirical model that relates the yield of biodiesel to the studied factors was obtained. The model has high statistical significance at $95 \%$ confidence interval with $R^{2}$ and adjusted $R^{2}$ values of $96.31 \%$ and $95.75 \%$ respectively. Results showed that among the three studied factors, the methanol-oil molar ratio had the greatest contribution to the yield of dairy effluent scum derived biodiesel followed by reaction temperature and finally, the catalyst concentration. Significant interaction effects were also present between methanol-oil ratio and catalyst, catalyst and reaction temperature and methanol-oil ratio and reaction temperature. Accordingly, the optimal variable settings were $14.355: 1$ methanol-oil molar ratio, 3.09\% catalyst loading by weight of pre-treated dairy scum oil and $55.20^{\circ} \mathrm{C}$ reaction temperature; with a corresponding yield of $92.72 \%$.
\end{abstract}

Keywords Biodiesel · Dairy effluent scum · Transesterification · Response surface methodology · Central composite rotatable design . Calcined eggshell

\section{Introduction}

Dairy effluent scum is a floatable material skimmed from the surface of primary and secondary settling tanks in dairy effluent treatment plants. It consists of residual milkrelated fats, proteins, soaps associated with the cleaning process, lipids and other impurities and is generated upon cleaning of equipment used to produce dairy products [1]. A typical dairy processing plant in a developing country processes up to $5000 \mathrm{~L}$ of effluent per day and produces approximately 200-350kgs of effluent scum per day. Disposal of the scum is associated with high costs due to the need for pumping and subsequent transport to solid waste disposal sites. Previous studies have shown that dairy effluent scum can be used as a feed stock for the synthesis of biodiesel [2]. In many instances dairy processing plants also produce salad creams as part of their product mix. Salad cream products require the use of thousands of eggs per day as raw material. Disposal of the egg shells results in serious land pollution, foul odours as a result of microbial action [3] and high costs of disposal. Calcium oxide $(\mathrm{CaO})$ can be derived from eggshells by calcination and the resultant calcine can be used to catalyze the synthesis of biodiesel [4]. Catalino et al. [5] investigated the production of biodiesel from soybean oil and waste frying oils using calcined calcium rich food wastes such as mollusk, shrimp, egg shell and cuttlebone as catalysts. They observed that the XRD diffraction lines for their catalysts were typical of lime with slight contaminations of calcite. The calcined catalyst can easily be separated from the reaction mixture

$\triangle$ P. K. Kuipa, kuipapardon@yahoo.com | 'Department of Chemical Engineering, National University of Science and Technology, Bulawayo, Zimbabwe. ${ }^{2}$ Lupane State University, Lupane, Zimbabwe. 
and regenerated for several reaction cycles $[6,7]$. The use of a solid catalyst reduces the volume of wash water and organic solvent required during the purification step of the biodiesel product [8]. Additionally, transesterification reactions occur approximately 4000 times faster in the presence of alkaline catalysts than in the presence of the same amount of acid catalyst [9]. However, some researchers have cautioned that the use of base catalysts for the transesterification reaction may cause problems due to saponification side reactions [10]. The problem is particularly pronounced when the oil feedstock has a high concentration of fatty acids and water [11]. The oxygen ions on the $\mathrm{CaO}$ surface have also been reported to form hydrogen bonds with methanol and glycerol, resulting in an increase in viscosity and the formation of a colloidal suspension of the $\mathrm{CaO}$ in the glycerol, making it difficult to separate the $\mathrm{CaO}$ and glycerol from the biodiesel product [12]. These disadvantages are offset by benefits such as low products costs, faster reaction speed and mild reaction conditions [13].

Previous studies by several researchers has demonstrated that the Response Surface Methodology (RSM) using a Central Composite Rotatable Design (CCRD) is an effective modelling and optimization tool to determine the important operating parameters for a given process [14]. The underlying theory and fundamental aspects of the Response Surface Methodology using a Central Composite Rotatable Design are well documented in the literature but the main advantage of this technique is the reduced number of experimental trials required to evaluate multiple parameters and their interactions [15, 16]. CCRD allows the building of a second order model by a smart placement of points in space. The quadratic terms are generated by the axial points which are rotatable thus ensuring that the variance of the model prediction is constant at all points equidistant from the centre. CCRD eliminates redundant observations, resulting in reduced experimental time and resources.

In the base catalyzed transesterification process the feedstock must be free of water and Free Fatty Acids (FFA), otherwise soap formation would reduce biodiesel yields [17]. For a base catalyzed transesterification process, when the FFA content in the feedstock is higher than three percent weight, the acidity must be lowered by neutralization with an alkaline compound or by esterification with methanol as a reagent in the presence of an acid catalyst $[18,19]$. Conventionally, FFA is neutralized with hot caustic soda at temperatures between 70 and $90^{\circ} \mathrm{C}$. The aim of the present work was to develop a new milk scum to biodiesel process that uses eggshell derived $\mathrm{CaO}$ as a transesterification catalyst as well as the neutralizing agent for FFA in the feedstock. $\mathrm{CaO}$ being a base is able to neutralize the FFA present within the milk scum feedstock. The optimal conditions for the production of biodiesel from the developed process are reported. The Central Composite Rotatable Design and the Response Surface Methodology were used to design the experiments, build the second order model and determine the optimum conditions. The influence of three reaction parameters (methanol to oil molar ratio, catalyst concentration and reaction temperature) was investigated. Results were evaluated using the Minitab-18 Statistical Package. The rest of the article is organized as follows: Sect. 2 describes the materials and methods employed by the authors. Section 3 reports the results and provides a discussion of the results. Section 4 concludes the research study and provides useful comments on future works.

\section{Materials and methods}

\subsection{Materials used for the production of biodiesel}

The Dairy Effluent Scum and eggshells were collected from a local milk and milk products processing plant (Dairibord Zimbabwe Private Limited, Harare, Zimbabwe). The reagents that were used for the study such as methanol, heptane and ethanolic $\mathrm{KOH}$ were of analytical reagent (AR) grade and were purchased from Fisher Scientific and Sigma-Aldrich. Absolute (anhydrous) ethanol (99.9\%) was of food grade and was purchased from EthanolSA, South Africa. All other reagents such as phenolphthalein indicator were of analytical grade.

\subsection{Methods}

\subsubsection{Sampling of dairy scum and chicken eggshells}

Grab samples of dairy scum were skimmed at 8 equidistant points with a step change of $0.5 \mathrm{~m}$ along the central position length of each of the four rectangular effluent settling tanks using a fabricated $1.5 \mathrm{~L}$ container. New polythene bags were used to store the daily samples in a coldroom. Daily samples were collected for a period of 30 days and added daily to make a composite monthly sample. The sample was refrigerated at a temperature of $-18^{\circ} \mathrm{C}$ during the period of sample collection. This procedure was repeated for three months over which the composition of the samples was realized to be almost consistent after characterization. A $3 \mathrm{~kg}$ composite sample collected in the third month was then analysed using standard procedures.

Eggshells were collected, washed, sun dried and crushed using a pestle and mortar and sieved using a 350 mesh sieve set. 


\subsubsection{Calcined eggshell powder preparation}

The dried eggshell powder was calcined in a muffle furnace at temperatures ranging from 700 to $900{ }^{\circ} \mathrm{C}$ and times ranging from 1 to $5 \mathrm{~h}$ to determine the optimum calcination conditions using a visual inspection of the resultant calcine's colour in comparison with the colour of a commercial sample of calcium oxide. The calcine that was used as the catalyst was characterised using XRF.

\subsubsection{Extraction of dairy scum oil}

The $3 \mathrm{~kg}$ composite sample of dairy scum was molten on a hot plate at a temperature of $45^{\circ} \mathrm{C}$. The melted sample was filtered using mutton cloth to remove unmelted solids. A $250 \mathrm{~g}$ sample of the filtered molten dairy scum was placed in a IL graduated beaker into which $250 \mathrm{~mL}$ of heptane was also placed. The mixture was gently stirred with a glass stirrer to mix the heptane and molten scum. The mixture was transferred to a separating funnel and left for $24 \mathrm{~h}$ to effect separation. The top layer containing heptane and oil was collected and bleached with egg shell powder. The use of heptane to pretreat the scum oil eliminates problems associated with water in the sample. The bleaching agent used in the present study is capable of neutralizing the Free Fatty Acids present in the scum oil and removing impurities by surface adsorption. For the bleaching step $12.5 \mathrm{~g}$ of the $\mathrm{CaO}$-rich eggshell calcine was added to $250 \mathrm{~g}$ of extracted scum-oil in a $400 \mathrm{~mL}$ beaker at $85^{\circ} \mathrm{C}$ and mixed using a magnetic stirrer for $15 \mathrm{~min}$. The bleached scum-oil eggshell calcine mixture was then transferred to a separating funnel and left to settle for $3 \mathrm{~h}$. The bleached scum oil was then separated from the eggshell calcine by filtration and washed several times with distilled water to remove any residual soaps and residual eggshell calcine. The bleached oil rich phases were distilled at a temperature of $100^{\circ} \mathrm{C}$ to recover heptane for reuse and were subsequently used for the transesterification experiments.

\subsubsection{Biodiesel production by transesterification}

Transesterification runs were carried out in accordance with Table 4. For each run within the CCRD, the catalyst was added to methanol within a $50 \mathrm{~mL}$ beaker and mixed gently with a glass rod. $20 \mathrm{~g}$ of pretreated scum-oil was preheated on a hot plate to about $50^{\circ} \mathrm{C}$ for $3 \mathrm{~min}$. The mixture was stirred on a hot plate with magnetic stirrer at $500 \mathrm{rpm}$ for $1 \mathrm{~h}$. The temperature of the mixture was constantly monitored using a thermometer. The reaction was stopped through quenching using cold water and the catalyst was separated by filtration. The reaction mixture was then transferred to a $100 \mathrm{~mL}$ separating funnel and left to settle for $24 \mathrm{~h}$. The biodiesel layer was separated, washed with hot distilled water 4 times to remove residues of catalyst and unreacted methanol. The washed methyl ester was then dried at $105^{\circ} \mathrm{C}$ on a hot plate for $30 \mathrm{~min}$ to remove moisture and residual methanol. The methyl ester was weighed and the Percentage Yield of biodiesel was calculated using Eq. 1.

Yield of biodiesel $=\frac{\text { Weight of biodiesel produced }}{\text { Weight of bleached scum oil }} \times 100 \%$

\subsubsection{Free fatty acid content and acid value of the bleached scum oil}

The free fatty acid (FFA) content of the oil is related to its acid value. The acid value of an oil sample is the number of milligrams of potassium hydroxide necessary to neutralise the acids present in one gram of the sample. The acid value of the bleached scum oil was determined by a standard titrimetric method involving titration of a known quantity of the oil with standard $\mathrm{KOH}$ solution. The acid value is determined as:

Acid value $=\frac{V * N * 56.1}{W} \mathrm{mgKOH} \mathrm{g}^{-1}$

where $\mathrm{V}=$ volume of standard $\mathrm{KOH}$ solution consumed, $\mathrm{N}=$ Normality of the standard $\mathrm{KOH}$ solution and, W $=$ weight of oil used.

The Free fatty acid content is derived from the acid value.

FFA $($ wt $\%$ Oleic Acid $)=\frac{\text { Acid value }}{2}$

\subsubsection{Saponification Value of the Bleached Scum Oil}

The saponification value (SV) is the number of milligrams of $\mathrm{KOH}$ required to completely hydrolyse (saponify) one gram of the oil. The saponification value is an indicator of the total acid content (both free and esterified) of the oil. A known amount of oil was refluxed with a known amount $0.5 \mathrm{~N}$ ethanolic $\mathrm{KOH}$ solution and the unused $\mathrm{KOH}$ was titrated against a standard $0.5 \mathrm{~N} \mathrm{HCl}$ solution. The saponification value was caluculated as:

$\mathrm{SV}=\frac{\left(\mathrm{V}_{\mathrm{KOH}}-\mathrm{V}_{\text {titre }}\right) 28.05}{\mathrm{~W}}$

where $\mathrm{V}_{\mathrm{KOH}}=$ volume of excess $0.5 \mathrm{~N}$ ethanolic $\mathrm{KOH}$ used, $\mathrm{V}_{\text {titre }}=$ volume of $0.5 \mathrm{~N} \mathrm{HCl}$ solution consumed during the titration and, $\mathrm{W}=$ weight of oil used. 


\subsubsection{Moisture content of the bleached scum oil}

The moisture content of the oil was determined by recording the weight loss of a known quantity of oil when it was dried in an oven at $105^{\circ} \mathrm{C}$ for $3 \mathrm{~h}$.

\subsection{Response Surface Methodology (RSM)}

Reaction variables were optimised using RSM whereas regression equation analysis was used to evaluate the response surface model [20].

$y=\beta_{o}+\sum_{j=1}^{k} \beta_{j} x_{j}+\sum_{j=1}^{k} \beta_{j j} x_{j}^{2}+\sum \sum_{i<j}^{k} \beta_{i j} x_{i} x_{j}+\epsilon$

where $y$ is the predicted biodiesel yield (in percentage), $\beta_{\mathrm{o}}, \beta_{\mathrm{j}}, \beta_{\mathrm{jj}}$ and $\beta_{\mathrm{ij}}$ represent the regression coefficients for the intercept, linear term, quadratic term and the interactive term respectively; $x_{i}$ and $x_{j}$ are coded independent variables, and $\epsilon$ is the model error.

\subsection{Central Composite Rotatable Design (CCRD)}

CCRD was used to design the experiments. CCRD is well documented as an effective experimental design technique which may be used as an alternative to factorial design as it requires far fewer experiments than the latter in order to adequately describe the majority of steady process responses. The number of tests required for CCRD include the standard $2^{k}$ factorial points with their origin at the centre(where $k$ is the number of variables), $2 k$ points fixed axially at a distance of $\beta$ from the centre to generate the quadratic terms and $\mathrm{n}_{c}\left(\mathrm{n}_{c} \approx 0.8385\left(2^{\frac{k}{2}}+2\right)^{2}-2^{\mathrm{k}}-2 \mathrm{k}\right)$ replicate points at the centre. The value of $\beta$ is the distance in coded variables from the design centre to an axial point. In general, for a $C C R D, \beta= \pm \sqrt[4]{F}$ where $F=2^{k}$. Thus, the value of $\beta=$ $\pm \sqrt[4]{8}=1.682$ for a CCRD with three factors that was applied in this study. The axial points should allow rotatability in order to ensure that the variance of the model prediction is constant at all points that are equidistant from the design centre. Replicates of the test at the centre provide an independent estimate of the experimental error. For this work, 3 factors were considered and therefore the total number of design points (base runs) for a CCRD with 3 factors $(k=3)$ was 20 . For a more accurate approximation of the polynomial model the 20-run CCRD was replicated in 5 blocks, hence, the total number of runs for the whole optimization study was 100 .

The independent variables are coded to lie at \pm 1 for the factorial points, 0 for the centre points and $\pm \beta$ for the axial points. The codes are a function of the range of each independent variable under study (see Table 1).

The relationships in Table 1 were used to calculate the values of the codes as is listed in Table 2 . The values of the codes were then used to determine the actual levels of the variables for each of the 20 experiments (Table 4). In order to obtain the required data, the range of values of each of the three variables was defined as follows: methanol to oil molar ratio of 3.645-14.355, catalyst concentration of 1.48-9.52 wt\% and temperature of 37.17-72.84 ${ }^{\circ} \mathrm{C}$.

Table 3 shows the summary of the key parameters that describe this CCRD. Listed are: the number of factors in the design, the base runs, base blocks, replicates, total blocks, total runs, value of $\beta$ chosen, and finally the total numbers of factorial, centre and axial points within the design.

The Central Composite Rotatable Design (CCRD) Experimental Matrix is shown in Table 4 below.

\section{Results and discussion}

\subsection{Characterization of the catalyst}

The visual characteristics of the calcines obtained at various combinations of temperatures and processing times are described in the Table 5 below.

Calcine 12 was the catalyst that was used for this work and was characterized using XRF to yield the following results (Table 6).

The results indicate that the calcine is predominantly $\mathrm{CaO}$. A calcination time of $3 \mathrm{~h}$ and a calcination temperature of $900{ }^{\circ} \mathrm{C}$ are in agreement with the reported time and temperature of $2.5 \mathrm{~h}$ and $900{ }^{\circ} \mathrm{C}$, respectively, for the calcination of eggshell for application in biodiesel production [22].

Table 1 Relationship between natural and coded variables [21].

\begin{tabular}{|c|c|}
\hline Code & Actual value of variable \\
\hline$-\beta$ & $x_{\min }$ \\
\hline-1 & $\frac{x_{\max }+x_{\min }}{2}+\frac{x_{\max }-x_{\min }}{2 \alpha}$ \\
\hline 0 & $\frac{x_{\max }+x_{\min }}{2}$ \\
\hline+1 & $\frac{x_{\max }+x_{\min }}{2}+\frac{x_{\max }-x_{\min }}{2 \alpha}$ \\
\hline$+\beta$ & $\mathrm{x}_{\max }$ \\
\hline \multicolumn{2}{|c|}{$\begin{array}{l}x_{\min } \text { and } x_{\max } \text { are the mini- } \\
\text { mum and maximum values of } \\
x \text {, respectively. } a=2 \mathrm{k} / 4 \text { where } \\
k=\text { number of variables }\end{array}$} \\
\hline
\end{tabular}


Table 2 Independent variables and their levels for CCRD

\begin{tabular}{|c|c|c|c|c|c|c|}
\hline \multirow[t]{3}{*}{ Variable } & \multirow{3}{*}{$\begin{array}{l}\text { Coded } \\
\text { symbol }\end{array}$} & \multicolumn{5}{|c|}{ Coded variable level } \\
\hline & & Lowest & Low & Centre & High & Highest \\
\hline & & $-\beta$ & -1 & 0 & +1 & $+\beta$ \\
\hline Methanol to oil molar ratio $(\mathrm{mol} / \mathrm{mol})$ & $X_{1}$ & 3.645 & 5.43 & 9.00 & 12.57 & 14.355 \\
\hline $\begin{array}{l}\text { Catalyst loading by weight of pre- } \\
\text { treated dairy scum oil (wt\%) }\end{array}$ & $x_{2}$ & 1.48 & 2.82 & 5.50 & 8.18 & 9.52 \\
\hline Reaction temperature $\left({ }^{\circ} \mathrm{C}\right)$ & $x_{3}$ & 37.17 & 43.11 & 55.00 & 66.89 & 72.84 \\
\hline
\end{tabular}

\begin{tabular}{ll}
\hline Term & Value \\
\hline Factors & 3 \\
Base runs & 20 \\
Base blocks & 1 \\
Replicates & 5 \\
Total blocks & 5 \\
Total runs & 100 \\
$\beta$ & 1.68179 \\
Factorial points & 40 \\
Centre points & 30 \\
Axial points & 30 \\
\hline
\end{tabular}

\subsection{Characteristics of the bleached dairy effluent scum oil}

The bleached oil had an acid value of $1.68 \mathrm{mg} \mathrm{KOH} / \mathrm{g}$ (from an initial value of $21.987 \mathrm{mgKOH} / \mathrm{g}$ before the bleaching/neutralization and washing steps), a saponification value of $154.75 \mathrm{mgKOH} / \mathrm{g}$ and a moisture content of $0.14 \% \mathrm{wt} / \mathrm{wt}$. An acid value below $3 \%$ indicates that calcium soap is not expected to form during the transesterification reaction. The saponification value is also relatively low, indicating the presence of predominantly longer chain oils. This means that the milk

Table 4 Central composite rotatable design (CCRD) experimental matrix

\begin{tabular}{|c|c|c|c|c|c|c|c|}
\hline \multirow[t]{2}{*}{ Design points type } & \multirow[t]{2}{*}{ Run no } & \multicolumn{3}{|c|}{ Coded variables } & \multicolumn{3}{|l|}{ Natural variables } \\
\hline & & $\mathrm{X}_{1}$ & $x_{2}$ & $x_{3}$ & $\begin{array}{l}\text { Methanol-oil ratio } \\
(\mathrm{mol} / \mathrm{mol})\end{array}$ & $\begin{array}{l}\text { Catalyst wt } \%= \\
\frac{\text { gcatalyst }}{20 \text { g scum oil }} \times 100 \%\end{array}$ & $\begin{array}{l}\text { Reaction } \\
\text { temperature } \\
\left({ }^{\circ} \mathrm{C}\right)\end{array}$ \\
\hline \multirow[t]{8}{*}{ Factorial points } & 1 & -1 & 1 & 1 & $5.43: 1$ & 8.18 & 66.89 \\
\hline & 2 & -1 & -1 & 1 & $5.43: 1$ & 2.82 & 66.89 \\
\hline & 3 & -1 & 1 & -1 & $5.43: 1$ & 8.18 & 43.11 \\
\hline & 4 & 1 & -1 & 1 & $12.57: 1$ & 2.82 & 66.89 \\
\hline & 5 & 1 & -1 & -1 & $12.57: 1$ & 2.82 & 43.11 \\
\hline & 6 & 1 & 1 & 1 & $12.57: 1$ & 8.18 & 66.89 \\
\hline & 7 & 1 & 1 & -1 & $12.57: 1$ & 8.18 & 43.11 \\
\hline & 8 & -1 & -1 & -1 & $5.43: 1$ & 2.82 & 43.11 \\
\hline \multirow[t]{6}{*}{ Axial points } & 9 & 0 & 1.68179 & 0 & $9.00: 1$ & 10.00 & 55.00 \\
\hline & 10 & 0 & -1.68179 & 0 & $9.00: 1$ & 1.00 & 55.00 \\
\hline & 11 & 1.68179 & 0 & 0 & $15.00: 1$ & 5.50 & 55.00 \\
\hline & 12 & -1.68179 & 0 & 0 & $3.00: 1$ & 5.50 & 55.00 \\
\hline & 13 & 0 & 0 & -1.68179 & $9.00: 1$ & 5.50 & 35.00 \\
\hline & 14 & 0 & 0 & 1.68179 & $9.00: 1$ & 5.50 & 75.00 \\
\hline \multirow[t]{6}{*}{ Centre points } & 15 & 0 & 0 & 0 & $9.00: 1$ & 5.50 & 55.00 \\
\hline & 16 & 0 & 0 & 0 & $9.00: 1$ & 5.50 & 55.00 \\
\hline & 17 & 0 & 0 & 0 & $9.00: 1$ & 5.50 & 55.00 \\
\hline & 18 & 0 & 0 & 0 & $9.00: 1$ & 5.50 & 55.00 \\
\hline & 19 & 0 & 0 & 0 & $9.00: 1$ & 5.50 & 55.00 \\
\hline & 20 & 0 & 0 & 0 & $9.00: 1$ & 5.50 & 55.00 \\
\hline
\end{tabular}


Table 5 Eggshell calcines after being subjected to varying calcination conditions

\begin{tabular}{|c|c|c|c|c|c|}
\hline Calcine & $\begin{array}{l}\text { Calcination tem- } \\
\text { perature }\left({ }^{\circ} \mathrm{C}\right)\end{array}$ & $\begin{array}{l}\text { Calcination time } \\
\text { (hrs) }\end{array}$ & $\begin{array}{l}\text { Initial mass of eggshell } \\
\text { powder }(\mathrm{g})\end{array}$ & $\begin{array}{l}\text { Final mass of calcined } \\
\text { eggshell powder }(\mathrm{g})\end{array}$ & Appearance \\
\hline 1 & 700 & 2 & 5.000 & 3.144 & Black and gray particles \\
\hline 2 & 700 & 3 & 5.000 & 3.005 & Pale white and gray mixture \\
\hline 3 & 700 & 4 & 5.000 & 2.987 & White with a few gray particles \\
\hline 4 & 750 & 1 & 5.000 & 3.197 & Gray and few white particles \\
\hline 5 & 750 & 4 & 5.000 & 2.955 & White with a few gray particles \\
\hline 6 & 750 & 5 & 5.000 & 2.898 & White \\
\hline 7 & 800 & 2 & 5.000 & 3.087 & Pale white \\
\hline 8 & 800 & 3 & 5.000 & 2.903 & White \\
\hline 9 & 850 & 1 & 5.000 & 3.066 & White with a few gray particles \\
\hline 10 & 850 & 2 & 5.000 & 2.907 & White \\
\hline 11 & 900 & 1 & 5.000 & 3.046 & White with a few gray particles \\
\hline 12 & 900 & 3 & 5.000 & 2.880 & Milky white \\
\hline
\end{tabular}

Table 6 XRF results for the characterization of chicken eggshell calcine

\begin{tabular}{ll}
\hline Parameter & Composition (\%) \\
\hline $\mathrm{SiO}_{2}$ & 0.65 \\
$\mathrm{Al}_{2} \mathrm{O}_{3}$ & 0.21 \\
$\mathrm{Fe}_{2} \mathrm{O}_{3}$ & 0.00 \\
$\mathrm{Mn}_{2} \mathrm{O}_{3}$ & 0.00 \\
$\mathrm{TiO}_{2}$ & 0.01 \\
$\mathrm{CaO}$ & 61.14 \\
$\mathrm{MgO}$ & 0.75 \\
$\mathrm{SO}_{3}$ & 0.28 \\
$\mathrm{~K}_{2} \mathrm{O}$ & 0.23 \\
$\mathrm{Na}_{2} \mathrm{O}$ & 0.05 \\
$\mathrm{L.O} . \mathrm{I}$ & 36.80 \\
\hline
\end{tabular}

scum oil is expected to consume less methanol and produce relatively less glycerol and more biodiesel during the transesterification reaction. It can be seen that the pre-treated milk scum oil is a suitable feedstock for biodiesel production, since it satisfies most of the requirements that a feedstock must satisfy for it to be viable for the production of biodiesel with acceptable fuel characteristics.

\subsection{Characteristics of the biodiesel derived from dairy effluent scum}

The washed methyl ester was dried and analysed for five parameters namely; specific gravity, calorific value, acid value, solubility and color. The results are shown in Table 7

\subsection{Central composite rotatable design results summary}

The statistical combination of the independent variables by central composite rotatable design along with the corresponding experimental response is presented in Table 8 .

Evaluation of the statistical significance of this CCRD model was done by using the F-test as shown in Table 9. The parameters on the columns are the degrees of freedom (DF), adjusted sum of squares (Adj SS), adjusted mean of squares (Adj MS), F-Value and its corresponding probability value (P-Value).

\section{Model summary}

\begin{tabular}{llll}
\hline Property & $\begin{array}{l}\text { Dairy scum bio- } \\
\text { diesel value }\end{array}$ & ASTM biodiesel standard & $\begin{array}{l}\text { ASTM petro- } \\
\text { leum diesel } \\
\text { standard }\end{array}$ \\
\hline Specific gravity & 0.865 & $0.84-0.87$ & 0.85 \\
Calorific value $(\mathrm{kJ} / \mathrm{kg})$ & 36,557 & - & 43,500 \\
Acid value $(\mathrm{mg} \mathrm{KOH} / \mathrm{g})$ & 0.7712 & $<0.8$ & 0.12 \\
Colour & Light Golden & Light Golden & Golden \\
Solubility in water & Insoluble & Insoluble & Insoluble \\
\hline
\end{tabular}

Table 7 Summary of dairy effluent scum derived biodiesel characteristics

SN Applied Sciences 


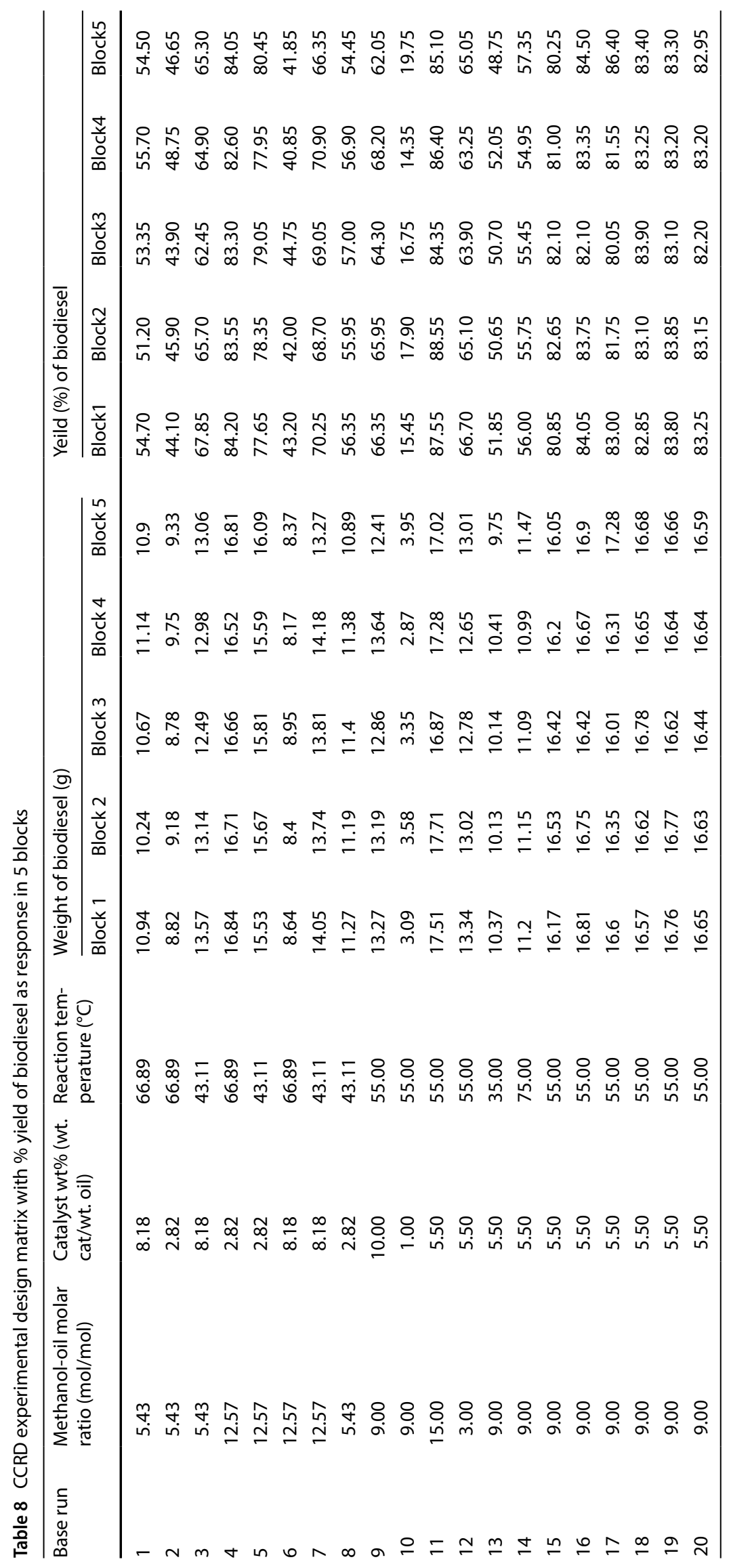


Table 9 Analysis of variance for the yield of biodiesel

\begin{tabular}{lrrlll}
\hline Source & DF & Adj SS & Adj MS & F-Value & P-Value \\
\hline Model & 13 & $23,488.7$ & 1806.83 & 172.43 & 0.000 \\
Blocks & 4 & 17.5 & 4.38 & 0.42 & 0.795 \\
Linear & 3 & 4199.5 & 1399.82 & 133.59 & 0.000 \\
A & 1 & 3936.9 & 3936.94 & 375.72 & 0.000 \\
B & 1 & 78.7 & 78.70 & 7.51 & 0.007 \\
C & 1 & 183.8 & 183.81 & 17.54 & 0.000 \\
Square & 3 & $13,493.8$ & 4497.93 & 429.26 & 0.000 \\
A*A & 1 & 460.7 & 460.74 & 43.97 & 0.000 \\
B*B & 1 & 7382.4 & 7382.45 & 704.54 & 0.000 \\
C*C & 1 & 7411.9 & 7411.88 & 707.35 & 0.000 \\
2-Way interaction & 3 & 5777.9 & 1925.98 & 183.80 & 0.000 \\
A*B & 1 & 4252.7 & 4252.67 & 405.85 & 0.000 \\
A*C & 1 & 135.9 & 135.94 & 12.97 & 0.001 \\
B*C & 1 & 1389.3 & 1389.33 & 132.59 & 0.000 \\
Error & 86 & 901.1 & 10.48 & - & - \\
Lack-of-Fit & 61 & 851.5 & 13.96 & 7.02 & 0.000 \\
Pure error & 25 & 49.7 & 1.99 & - & - \\
Total & 99 & $24,389.9$ & - & - & - \\
\hline
\end{tabular}

\begin{tabular}{llll}
\hline$S$ & R-sq & R-sq(adj) & R-sq(pred) \\
\hline 3.23704 & $96.31 \%$ & $95.75 \%$ & $94.72 \%$ \\
\hline
\end{tabular}

\subsection{Regression equation in natural variables}

where $\mathrm{Y}=\%$ Yield of Biodiesel, $\mathrm{A}=$ Methanol to oil molar ratio, $\mathrm{B}=$ Catalyst $\mathrm{wt} \%$, and $\mathrm{C}=$ Reaction Temperature.

Regression analysis was used to produce the experimental model, as given by Eq. 3, which relates the yield of biodiesel to the factors that were under study. This regression model has very high statistical significance at 95\% Confidence Interval with the correlation coefficients of determination R-Squared $\left(\mathrm{R}^{2}\right)$ and adjusted R-Squared of $96.31 \%$ and $95.75 \%$, respectively. This implies that the model explains greater than $95 \%$ of the variations in the yield of biodiesel when the three factors, namely; methanol-oil molar ratio, catalyst concentration and reaction temperature were varied. The results imply that the contribution of other factors that affect the yield of biodiesel such as the reaction time, moisture content and stirring speed were successfully suppressed for the range of experiments.

\subsection{Normality test}

The normality assumption has to be satisfied for a response surface model to be significant. Figure 1 shows a normal probability plot for the residuals in the yield of biodiesel. The plot for the residuals is linear and it may be concluded that the normality assumption was satisfied.

$Y=-333.4+14.035 A+35.06 B+9.160 C-0.1987 A^{2}-1.4138 B^{2}-0.07172 C^{2}-1.0801 A * B-0.0435 A * C-0.1852 B * C$

Fig. 1 Normal probability plot for residuals in yield of biodiesel

\section{Normal Probability Plot}

(response is Yield (\%))

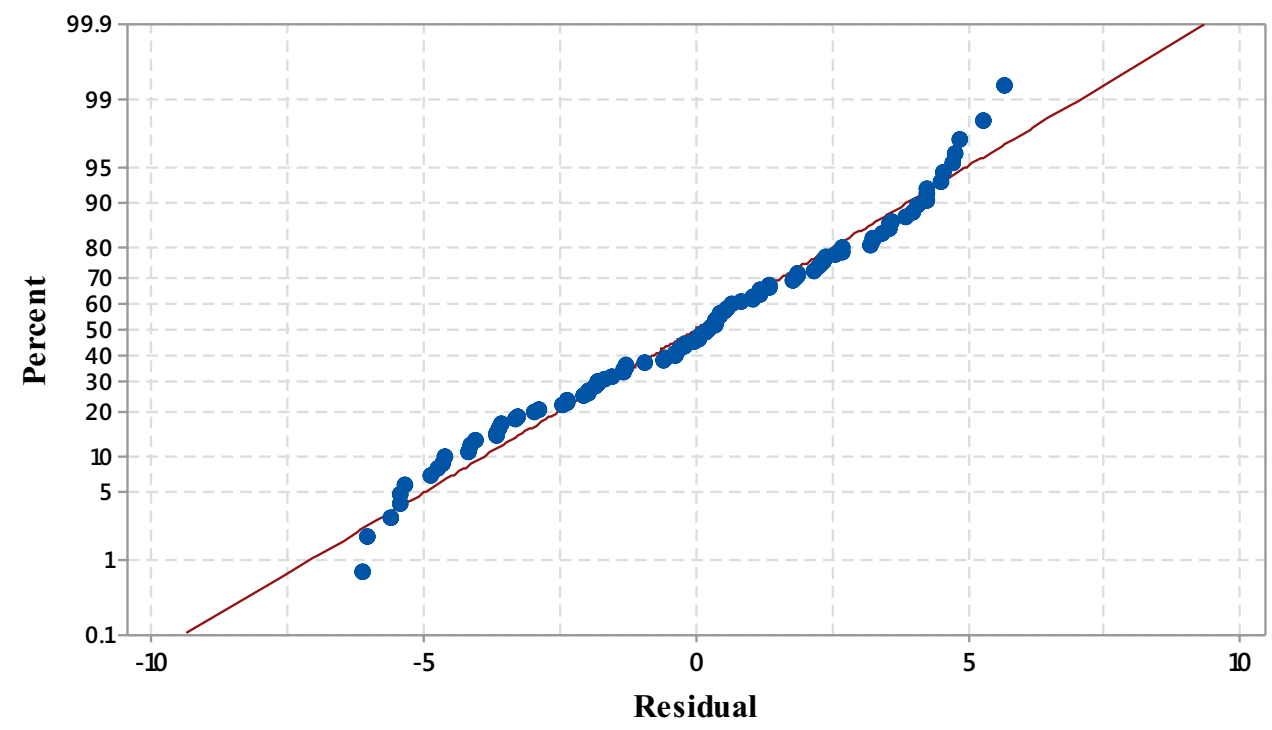




\subsection{Statistical significance tests of regression coefficients using the f-test}

Since the normality assumption was satisfied, the hypothesis test on the coefficients of the empirical model was carried out as follows:

\begin{tabular}{|c|c|c|c|c|c|}
\hline Let & $\mathrm{H}_{0}$ : & $B_{A}=0$ & & $\mathrm{H}_{1}:$ & $B_{A} \neq 0$ \\
\hline & $\mathrm{H}_{0}$ : & $B_{B}=0$ & & $\mathrm{H}_{1}$ : & $B_{B} \neq 0$ \\
\hline & $\mathrm{H}_{0}$ : & $B_{C}=0$ & & $\mathrm{H}_{1}:$ & $B_{C} \neq 0$ \\
\hline & $\mathrm{H}_{0}$ : & $\beta_{A^{*} B}=0$ & & $\mathrm{H}_{1}:$ & $B_{A^{*} B} \neq 0$ \\
\hline & $\mathrm{H}_{0}$ : & $\beta_{A^{*} C}=0$ & Versus & $\mathrm{H}_{1}$ : & $B_{A^{*} C} \neq 0$ \\
\hline & $\mathrm{H}_{0}$ : & $B_{B^{*} C}=0$ & & $\mathrm{H}_{1}:$ & $B_{B^{*} C} \neq 0$ \\
\hline & $\mathrm{H}_{0}$ : & $\beta_{A^{*} A}=0$ & & $\mathrm{H}_{1}$ : & $B_{A^{*} A} \neq 0$ \\
\hline & $\mathrm{H}_{0}$ : & $B_{B^{*} B}=0$ & & $\mathrm{H}_{1}:$ & $B_{B^{*} B} \neq 0$ \\
\hline & $\mathrm{H}_{0}$ : & $B_{C^{*} C}=0$ & & $\mathrm{H}_{1}:$ & $B_{C^{*} C} \neq 0$ \\
\hline
\end{tabular}

Where $\mathrm{H}_{0}$ and $\mathrm{H}_{1}$ are the null and alternative hypotheses respectively; and the $B$ terms represent the coefficients of the model terms on their subscripts.

With reference to Table 8 , at the $5 \%$ significance level $(p=0.05)$, all the P-values corresponding to all the terms in the model are less than 0.05 . Thus, there is significant statistical evidence to reject the null hypotheses and conclude at $5 \%$ significance level that the terms $A, B, C$, $A^{*} B, A^{*} C, B^{*} C, A^{2}, B^{2}$ and $C^{2}$ contribute significantly to the empirical model for the yield of dairy scum biodiesel. Additionally, the P-value for the Blocks, P-value $=0.795$, is greater than 0.05 . This implies that blocking the experimental design had no significant effect on the yield of biodiesel and thus the block effect does not appear in the model given in Eq. 3 .

\subsection{Relative contributions of each factor to the yield of biodiesel}

Although the three factors under study were jointly contributory to the yield of biodiesel, their main effects were significantly different. Figure 2 shows a main effects plot that depicts the relative contributions of each factor to the yield of biodiesel.

\subsubsection{Effect of methanol-oil ratio on the yield of methyl biodiesel}

Figure 2 shows the main effect of methanol to oil ratio on the yield of dairy scum biodiesel. Generally, an increase in the methanol-oil molar ratio resulted in an increase in the yield. This is because a sufficient amount of alcohol is required for the complete breakage of glycerin and fatty acid linkages [23]. Considering Fig. 4 and 5 below, which provide an illustration of the combined effect of Methanol-Oil Molar Ratio and Reaction Temperature at 5.5 wt\% catalyst, it is apparent that the yield increased from a region $<20 \%$ to a region $>90 \%$ corresponding to molar ratios of 3:1 to 14.355:1 respectively.

\subsubsection{Effect of catalyst wt\% on the yield of biodiesel}

From the main effects plot on Fig. 2, a relatively substantial effect of $\mathrm{CaO}$ catalyst is shown from $1.00 \%$ to $5.50 \%$ where a small increase in catalyst loading results in a significant
Fig. 2 Main effects plot for yield of biodiesel showing the relative effect of each factor on the yield of biodiesel

\section{Main Effects Plot for Yield of Biodiesel (\%)}

Data Means

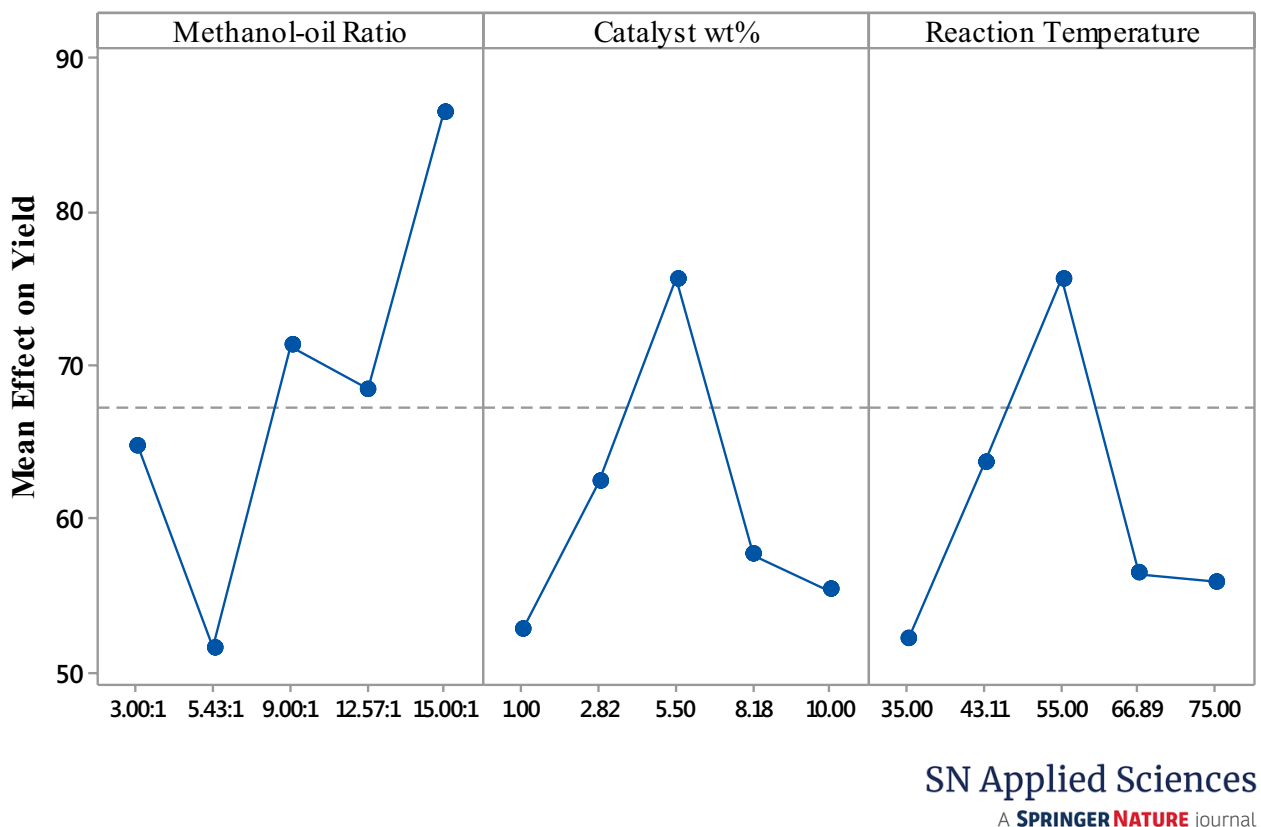


increase in the yield of biodiesel. Higher concentrations of the catalyst would support side reactions such as saponification; thus an increase in soap content was observed within the product. A further analysis of the main effects plot in Fig. 2 reveals that the yield of biodiesel decreases sharply by about $20 \%$ for catalyst concentrations in the range of $5.50 \mathrm{wt} \%$ to $8.80 \mathrm{wt} \%$. This trend is followed by a smaller decrease, in the yield, of about $5 \%$ from 8.18 wt $\%$ to $10.00 \mathrm{wt} \%$ catalyst loadings.

\subsubsection{Effect of reaction temperature on the yield of biodiesel}

The effect of reaction temperature is depicted on the main effects plot on Fig. 2. It was observed that an increase in reaction temperature favours methyl ester conversion, but temperatures higher than about $55^{\circ} \mathrm{C}$ have a main effect of lowering the yield of biodiesel. This relates to the fact that after $55^{\circ} \mathrm{C}$, temperatures approach the boiling point of methanol $\left(64.7^{\circ} \mathrm{C}\right)$ and thus, much of the alcohol evaporates from the reaction mixture thereby shifting the equilibrium to the left. In addition, although a higher reaction temperature can decrease the viscosities of oils as well as increase the transesterification reaction rate, it may decrease methyl ester yield because it accelerates the saponification of triglycerides [23].

\subsubsection{Interaction effects between the factors}

The interaction effects between the three factors on the yield of biodiesel are depicted in the Pareto Chart in Fig. 3 and their response surface plots and corresponding contour plots. A total of three interactions between factors were studied; Methanol-oil Ratio and Catalyst wt $\%\left(A^{*} B\right)$, Methanol-oil Ratio and Reaction Temperature $\left(A^{*} C\right)$, as well as Catalyst wt\% and Reaction Temperature $\left(B^{*} C\right)$.

On the Pareto Chart on Fig. 3, all the effects are greater than the critical value $t_{0.05}(99)=1.99$. The $A^{*} B$ interaction is greater than the $B^{*} C$ interaction and the $A^{*} C$ interaction is the least among the three. It follows that the interaction between the methanol-oil ratio and the catalyst wt $\%$ had a large effect on the yield of dairy scum biodiesel. This result may be explained by the fact that mixing methanol and $\mathrm{CaO}$ before reacting with scum oil may result in the formation of methoxide anions which react with the $\mathrm{CaO}$ to form calcium methoxide on the surface of the $\mathrm{CaO}$ particles. Catalino et al. [5] reported that the XRD diffraction lines for the post-reaction calcium oxide catalyst were typical of mainly calcium diglyceroxide and calcium methoxide. The calcium methoxide has been reported to have better catalytic activity than $\mathrm{CaO}[24,25]$. It is not soluble in methanol but forms a suspensoid with well-developed surface active sites [24]. The higher activity of the calcium methoxide catalyst for the transesterification reaction results in higher yields of the biodiesel.

\subsubsection{Effect of methanol-oil ratio and catalyst wt\% on the yield of biodiesel}

The joint effect of methanol-oil ratio and catalyst wt $\%$ on the yield of biodiesel was studied at a constant temperature of $55^{\circ} \mathrm{C}$. The response surface plot and contour plot showing the interaction between these variables are shown in Figs. 4 and 5, respectively. Figure 4 shows the
Fig. 3 A depiction of the standard effects of variables within the RSM model

\section{Pareto Chart of the Standardized Effects}

(response is Yield (\%), $\alpha=0.05$ )

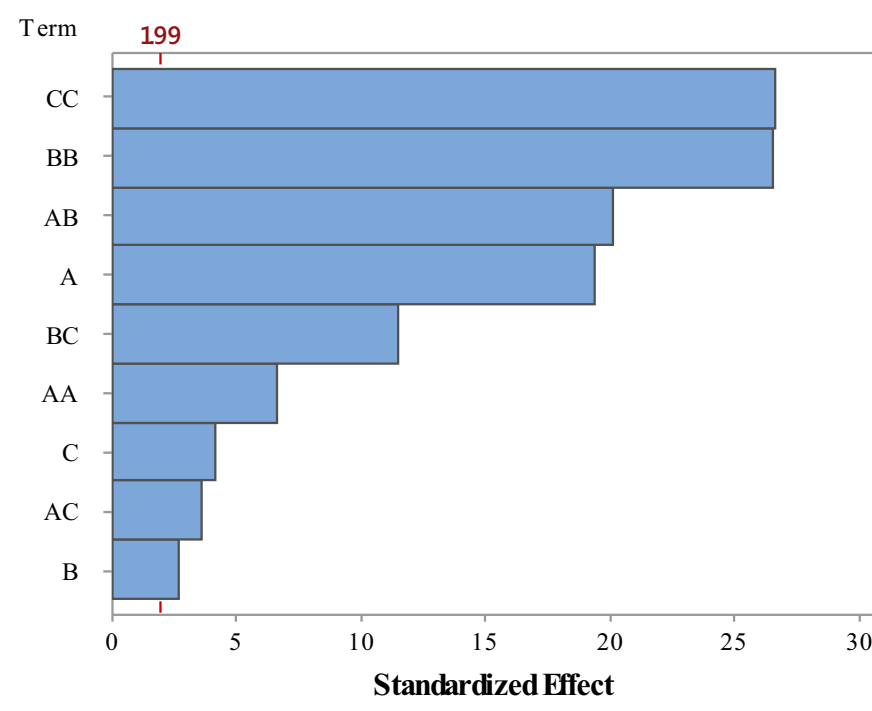

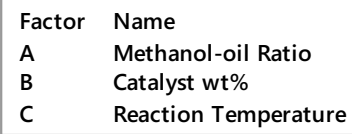


Fig. 4 Response Surface plot illustrating the combined effect of Methanol-oil Molar Ratio and Catalyst loading at $55^{\circ} \mathrm{C}$ on the yield of biodiesel

\section{Surface Plot of Yield (\%) vs Catalyst wt\%, Methanol-oil Ratio}

Hold Values

Reaction Temperature55

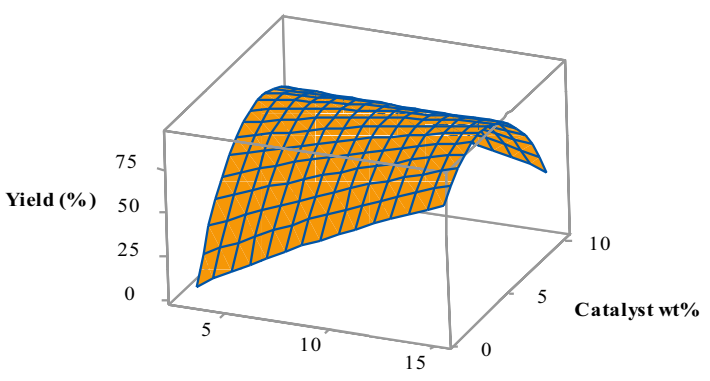

Methanol-oil Ratio (mol/mol)
Fig. 5 Contour plot illustrating the combined effect of methanol-oil molar ratio and catalyst loading at $55^{\circ} \mathrm{C}$

\section{Contour Plot of Yield (\%) vs Catalyst wt\%, Methanol-oil Ratio}

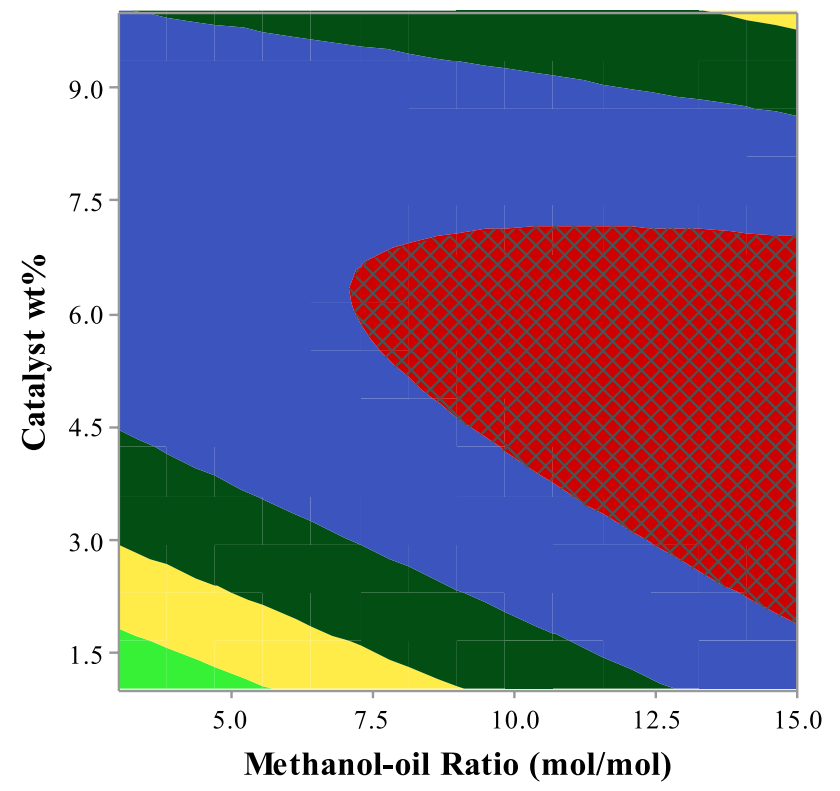

Hold Values

Reaction Temperature 55 shape of the response surface while Fig. 5 shows a contour plot of the yield. Figures 4 and 5 show that the maximum yield of biodiesel (> $80 \%$ ) is obtained within the mid ranges of the catalyst wt $\%$ and at higher values of the methanol-oil molar ratio. Furthermore, it can be seen that at the temperature of $55^{\circ} \mathrm{C}$, increasing the methanol-oil molar ratio at constant catalyst wt $\%$ generally improves the yield of biodiesel. This suggests that the methanol-oil ratio generally has a greater effect on the yield of biodiesel than the catalyst concentration. This trend may be explained by the fact that methanol is a main reactant in the transesterification process whereas the catalyst acts only to speed up the reaction rate.

\subsubsection{Effect of methanol-oil ratio and reaction temperature on the yield of biodiesel}

The combined effect of methanol-oil ratio and reaction temperature on the yield of biodiesel was studied at a constant catalyst concentration of $5.5 \mathrm{wt} \%$. The response surface plot 
Fig. 6 Response surface plot illustrating the combined effect of methanol-oil molar ratio and reaction temperature at 5.5 wt $\%$ catalyst loading on the yield of biodiesel
Surface Plot of Yield (\%) vs Reaction Temperature, Methanol-oil Ratio

Hold Values

Catalyst wt \% 5.5

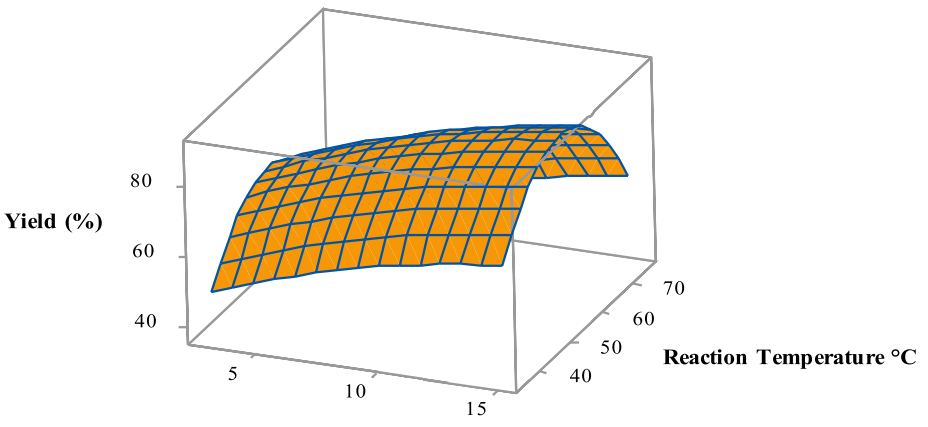

Methanol-oil Ratio (mol/mol)
Fig. 7 Contour plot illustrating the combined effect of methanol-oil molar ratio and reaction temperature at $5.5 \mathrm{wt} \%$ catalyst loading on the yield of biodiesel

\section{Contour Plot of Yield (\%) vs Reaction Temperature, Methanol-oil Ratio}

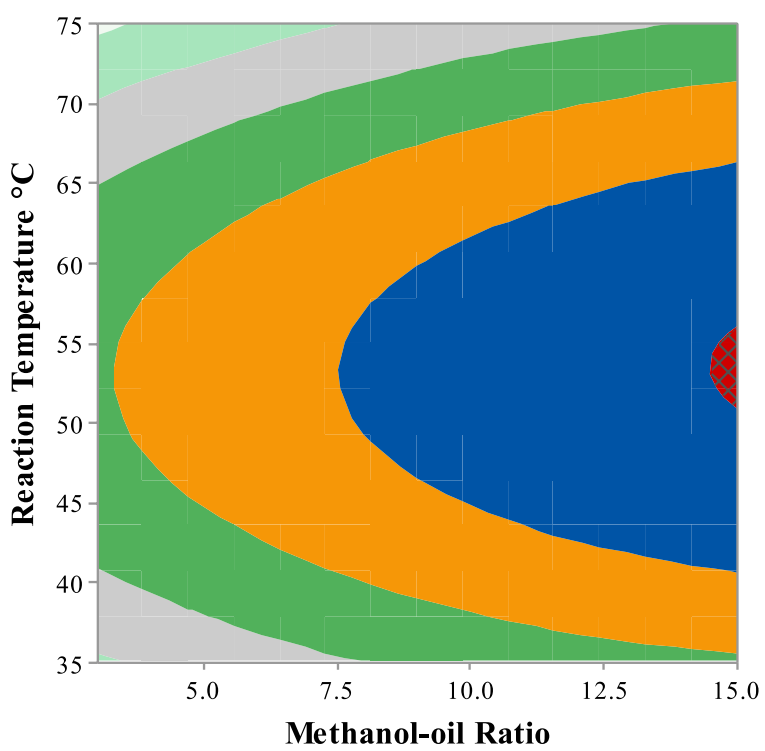

Yield

(\%)

$<40$

$40-50$

$50-60$

$60-70$

$70-80$

$80-90$

$>90$

Hold Values

Catalyst wt $\% \quad 5.5$ and contour plot showing the interaction between these variables are shown in Fig. 6 and 7 respectively.

The highest yield region is shown to be very small on the contour plot on Fig. 7 and it can be enlarged by increasing the methanol-oil ratio beyond the design upper limit of 14.355:1. In this interaction, methanol-oil ratio has a more dominant role than the reaction temperature in its contribution to the yield of biodiesel.

\subsubsection{Effect of catalyst wt $\%$ and reaction temperature on the yield of biodiesel}

The combined effect of catalyst wt $\%$ and reaction temperature on the yield of biodiesel was studied at a constant methanol-oil molar ratio of 9:1. The response surface plot and contour plot showing the interaction between these variables is shown in Figs. 8 and 9 respectively. 
Fig. 8 Response surface illustrating the combined effect of catalyst wt $\%$ and reaction temperature at methanol-oil molar ratio of 9:1 on the yield of biodiesel

\section{Surface Plot of Yield (\%) vs Reaction Temperature, Catalyst wt\%}

Hold Values

Methanol-oil Ratio 9

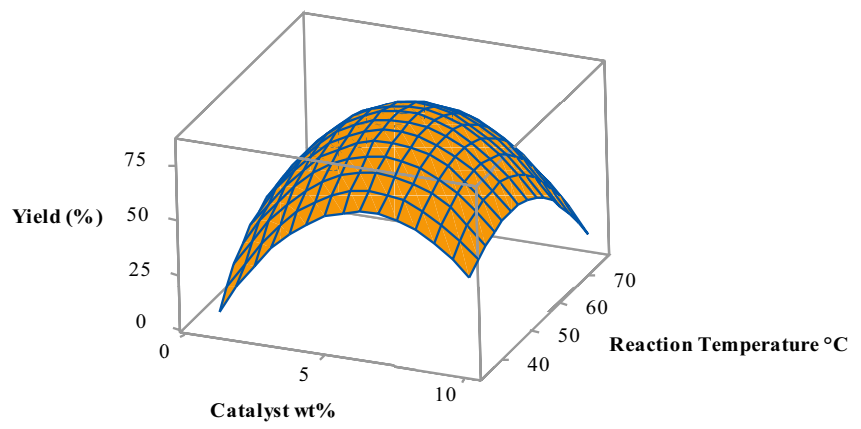

Fig. 9 Contour plot illustrating the combined effect of catalyst wt $\%$ and reaction temperature at methanol-oil molar ratio of 9:1 on the yield of biodiesel

\section{Contour Plot of Yield (\%) vs Reaction Temperature, Catalyst wt\%}

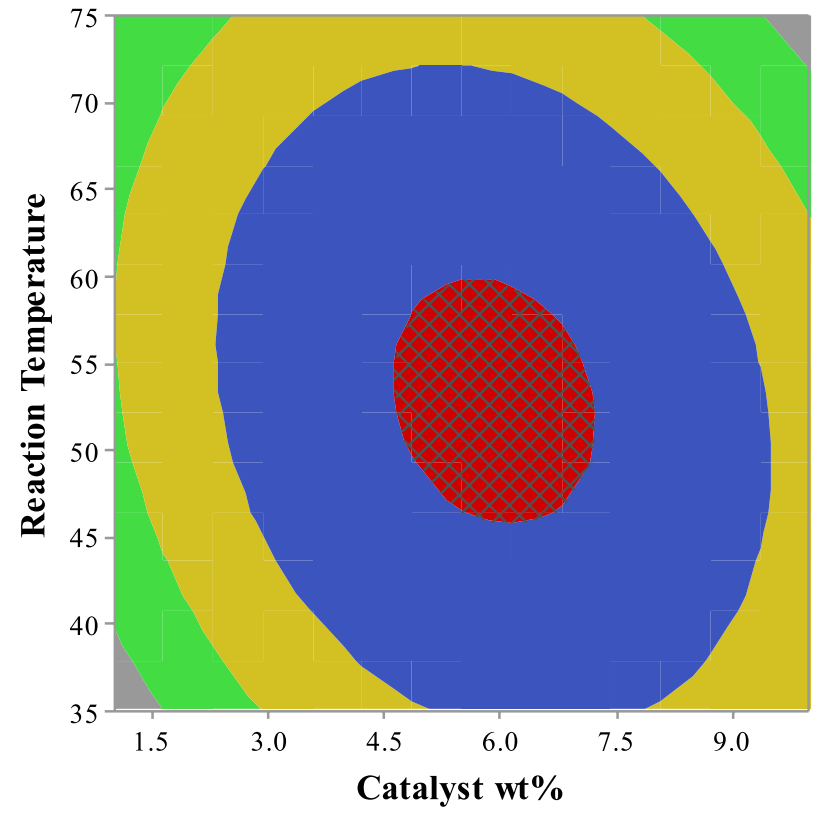

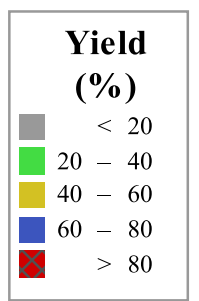

Hold Values Methanol-oil Ratio 9
The shape of the response surface in Fig. 8 is parabolic while the contour lines shown in Fig. 9 are concentric ovals. This implies that the contributions of the reaction temperature and the catalyst wt $\%$ to their joint effect on biodiesel yield are comparable. Thus, at a constant methanol-oil molar ratio of 9:1, the optimum region (> $80 \%$ ) lies in the middle of both the reaction temperature and catalyst wt $\%$ design ranges. This result is consistent with findings by Prasertsit et al. [25] on the transesterification of palm oil using $\mathrm{CaO}$ catalyst.

\subsubsection{Simulated optimum settings for maximum yield of biodiesel}

The optimum variable settings with the goal of maximizing the yield of biodiesel were computed by Minitab Response Surface Optimizer as given in Table 8. The analysis at $95 \%$ confidence interval shows that the maximum predicted yield of biodiesel is $96.79 \%$ for the following variable settings: methanol-oil ratio of $14.355: 1$, catalyst $w t \%$ of $3.09 \%$ at a reaction temperature of $55.20^{\circ} \mathrm{C}$. 
The optimum setting for the methanol-oil molar ratio of 14.355:1 coincides with the design upper limit. A consideration of the latter fact, together with the shapes of the response surfaces in Fig. 4 and 6 where methanol-oil ratio interacts with other factors suggests that the methanoloil molar ratio can be increased to ratios above the design upper limit to probably result in a greater yield. The shapes of the response surfaces in particular depict an increase in yield of biodiesel along the methanol-oil ratio axis. This result closely relates with the work done by Prasertsit et al. [25] on the transesterification of palm oil using reagent grade $\mathrm{CaO}$ catalyst.

On the other hand, the optimum setting for the catalyst $w t \%$ of $3.09 \%$ is closer to the design lower limit (1\%) than the design upper limit of $10 \%$. This result suggests that the yield of biodiesel is lower at very low catalyst loadings less than the optimum. This may be explained by the fact that the amount of catalyst present will be insufficient to significantly speed up the rate of reaction. An increase in the catalyst concentration up to the optimum setting results in an increase in the response. This may be due to the increase in the total number of active sites for transesterification reaction that can speed up its rate. However, further increasing the catalyst loading lowers the yield because side reactions such as saponification are favoured as more $\mathrm{CaO}$ is present to react with the triglyceride to form calcium soap.

Finally, the optimum setting for the reaction temperature $\left(55.20^{\circ} \mathrm{C}\right)$ confirms the fact that the yield of biodiesel is expected to be highest below the boiling point of the alcohol. The boiling point of methanol is $64.7^{\circ} \mathrm{C}$. Reaction temperatures higher than the boiling point of methanol resulted in lower yields of biodiesel as more methanol evaporated from the reaction mixture.

After the optimum settings had been found by modelling, they were experimentally tested and the variation in the yield at these settings was found to be almost constant with an average yield value of $92.72 \%$, though slightly below the model predicted value of $96.79 \%$.

\section{Conclusions}

Eggshells and dairy effluent scum present a lot of disposal challenges and their utilization may help in minimizing environmental pollution. Experimental results proved that dairy effluent scum is a viable feed stock for biodiesel production. The quality of the produced biodiesel was tested for a few properties which include density, solubility in water and acid value and these were found to be within the desired specifications. The application of Response Surface Methodology in optimizing the process parameters proved to be resourceful as the predicted optimum yield $(96.79 \%)$ at optimum settings was found to be comparable with the experimental biodiesel yield (92.72\%). Calcined chicken eggshell proved to be an effective transesterification catalyst as well as an efficient dairy effluent scum oil bleaching agent. Future works could include analysis of the catalyst to determine its crystallinity, morphology, surface area and how many times the catalyst maybe reused before requiring re-activation. Performance and emission characteristics of the obtained biodiesel in a compression ignition engine may also be investigated.

\section{Compliance with ethical standards}

Conflict of interest The authors declare that they have no conflict of interest.

Open Access This article is licensed under a Creative Commons Attribution 4.0 International License, which permits use, sharing, adaptation, distribution and reproduction in any medium or format, as long as you give appropriate credit to the original author(s) and the source, provide a link to the Creative Commons licence, and indicate if changes were made. The images or other third party material in this article are included in the article's Creative Commons licence, unless indicated otherwise in a credit line to the material. If material is not included in the article's Creative Commons licence and your intended use is not permitted by statutory regulation or exceeds the permitted use, you will need to obtain permission directly from the copyright holder. To view a copy of this licence, visit http://creativecommons .org/licenses/by/4.0/.

\section{References}

1. Sivakumar P, Anbarasu K, Renganathan S (2011) Bio-diesel production by alkali catalyzed transesterification of dairy waste scum. Fuel 90:147-151

2. Wang $Y$, Feng S, Bai X, Zhao J, Xia S (2016) Scum sludge as a potential feedstock for biodiesel production from wastewater treatment plants. Waste Manag 47:91-97

3. Tangboriboon N, Kunanuruksapong R, Sivirat A (2012) Preparation and properties of calcium oxide from eggshells via calcination. Mater Sci-Pol 30(4):313-322

4. Kesic Z, Lukic l, Zdujic M, Mojovic L, Skala D (2016) Calcium oxide based catalysts for biodiesel production: A review. ChemIndChemEng Quart 22(4):391-408

5. Catarino M, Ramos M, Dias AS, Santos MT, Puna JF, Gomes JF (2017) Calcium rich food wastes based catalysts for biodiesel production. Waste Biomass Valoriz 8:1699-1707

6. Marwaha A, Rosha P, Mohapatra SK, Mahla SK, Dhir A (2018) Waste materials as potential catalysts for biodiesel production: current state and future scope. Fuel Process Technol 181:175-186

7. Ghanei R, Dermani RK, Salehi Y, Mohammadi M (2016) Waste anaimal bone as support for $\mathrm{CaO}$ impregnation in catalytic biodiesel production from vegetable oil. Waste Biomass Valoriz 7:527-532

8. Correia LM, Cecilia JA, Rodriguez-Castellon E, Cavalcante CL Jr, Vieira RS (2017) Relevance of the physicochemical properties of 
calcined quail eggshell $(\mathrm{CaO})$ as a catalyst for biodiesel production. J Chem 2017:1-12

9. Yathish KV, Suresh R, Amruth E (2013) Optimization of biodiesel production from mixed oil (karanja \& dairy waste scum oil) using homogeneous catalyst. IOSR J ApplChem 3(6):09-15

10. Chouhan APS, Sarma AK (2011) Modern heterogeneous catalysts for biodiesel production: A comprehensive review. Renew Sustain Energy Rev 15(9):4378-4398

11. Siddiquee MN, Rohani S (2011) Lipid extraction and biodiesel production from municipal sewage sludges: a review. Renew Sustain Energy Rev 15(2):1067-1072

12. Helwani Z, Ramli M, Saputra E, Bahruddin B, Yolanda D, Fatra W, Idroes GM, Muslem M, Mahlia TMI, Idroes R (2020) Impregnation of $\mathrm{CaO}$ from eggshell waste with magnetite as a solid catalyst $\left(\mathrm{Fe}_{3} \mathrm{O}_{4} / \mathrm{CaO}\right)$ for transesterification of palm oil off-grade. Catalysts 10:164

13. Boey PL, Maniam GP, Hamid SA (2011) Performance of calcium oxide as a heterogeneous catalyst in biodiesel production: areview. ChemEng J 168:15-22

14. Moradi M, Fazlzadehdavil M, Pirsaheb M, Mansouri Y, Khosravi T, Sharafi K (2016) Response surface methodology (RSM) and its application for optimization of ammonium ions removal from aqueous solutions by pumice as a natural and low cost adsorbent. Arch Environ Prot 42(2):33-43

15. Boey PL, Maniam GP, Hamid SA, Ali DM (2011) Utilization of waste cockle shell (Anadara granosa) in biodiesel production from palm olein: optimization using response surface methodology. Fuel 90:2353-2358

16. Yatish KV, Lalithamba HS, Suresh R, Arun SB, Vinay Kumar P (2016) Optimization of scum oil biodiesel production by using response surface methodology. Process Saf Environ Prot 102:667-672

17. Granados ML, Zafra-Poves MD, Alonso DM, Mariscal R, Galisteo FC, Moreno-Tost R, Santamaria J, Fierro JLG (2007) Biodiesel from sunflower oil by using activated calcium oxide. Appl Catal B 73(3):327-336

18. Canakci M, Van Gerpen J (2001) Biodiesel production from oils and fats with high free fatty acids. Trans American SocAgricEng 44(6):1429-1436

19. Morais S, Mata TM, Martins AA, Pinto GA, Costa CAV (2010) Simulation and life cycle assessment of process design alternatives for biodiesel production from waste vegetable oils. J Clean Prod 18:1251-1259

20. Box GE, Draper NR (1987) Empirical model-building and response surfaces. Wiley, New York

21. Alireza AS, Ataallah SG, Majid EG, Amir S, Mohammad R, Hadi A (2013) Application of response surface methodology and central composite rotatable design for modeling the influence of some operating variables of the lab scale thickener performance. Int J Min SciTechnol 23:717-724

22. Niju S, Meera KM, Begum S, Anantharaman N (2014) Modification of egg shell and its application in biodiesel production. J Saudi ChemSoc 18:702-706

23. Rahees K, Meera V (2014) Production of biodiesel from waste. Int J SciEng Res 5(7):194-196

24. Gryglewicz S (1999) Rapeseed oil methyl esters preparation using heterogeneous catalysts. Biores Technol 70:249-253

25. Prasertsit K, Phoosakul P, Sukmanee S (2014) Use of calcium oxide in palm oil methyl ester production. Songklanakarin J SciTechnol 36(2):195-200

Publisher's Note Springer Nature remains neutral with regard to jurisdictional claims in published maps and institutional affiliations. 